\title{
EM BUSCA DAS ESCOLAS NA ESCOLA: POR UMA EPISTEMOLOGIA DAS "BALAS SEM PAPEL"
}

\author{
Alexandra Garcia*
}

\begin{abstract}
O olhar percorre as ruas como páginas escritas: a cidade diz tudo que devemos pensar, faz-nos repetir o seu discurso, e enquanto julgamos visitar Tamara limitamo-nos a registrar os nomes com que ela se define a si mesma e a todas as suas partes. Como realmente é a cidade sob esse denso invólucro de sinais, o que ela contém ou oculta, o homem sai de Tamara sem tê-lo sabido.
\end{abstract}

(Ítalo Calvino, As cidades invisiveis)

\begin{abstract}
RESUMO: O texto discute a produção de conhecimento no paradigma científico moderno a fim de ponderar sobre seus limites para acessar as nuances do cotidiano. Entende que, no rastro do cientificismo moderno seguido pelas ciências sociais, resignamo-nos e naturalizamos a prática de conhecer satisfazendo-nos e crendo em rótulos, embalagens que pretendem acessar e explicar o viver humano ordinário. Procura evidenciar a pertinência das opçôes que levam à proposição da pesquisa nos/dos/com os cotidianos como caminho, não como paradigma, para se compreender e valorizar os saberesfazeres das práticas cotidianas, não decifráveis por ângulos ou enquadramentos discursivos formais. Narrar experiências não é superestimar o que, pelo improvável aspecto "positivo", pareça-nos uma "ode ao desvio-padrão". Assumir os riscos de trazê-las implica acreditar que o ato de desestabilizar as concepções dominantes sobre a escola contribui para a pensarmos sem "pré-conceitos", longe das impossibilidades e da beira do abismo.
\end{abstract}

Palavras-chave: Pesquisa no/do/com o cotidiano. Cotidiano escolar. Emancipação social. Cientificismo.

Doutoranda pela Universidade do Estado do Rio de Janeiro (UERJ) e professora adjunta da Escola de Educação da Universidade Grande Rio (UNIGRANRIO). E-mail: alegarcialima@hotmail.com

Educ. Soc., Campinas, vol. 28, n. 98, p. 129-147, jan./abr. 2007

Disponível em <http://www.cedes.unicamp.br> 
Em busca das escolas na escola: por uma epistemologia das "balas sem papel"

\author{
IN SEARCH OF SCHOOLS WITHIN SCHOOL: \\ FOR AN EPISTEMOLOGY OF "UNWRAPPED CANDY"
}

ABSTRACT: This paper discusses the knowledge production in the modern scientific paradigm to ponder over its limits and to access nuances of the quotidian. It assumes that, in the wake of the modern scientific approach followed by the social sciences, we resign and understand as natural the practice of experience satisfying ourselves and believe in labels and packages that intent to access and explain the ordinary human living. It tries to evidence the importance of options leading to propose research in/of/with the quotidian, like a way, rather than a paradigm, to understand and value the knowledgedoings of the everyday practices, that cannot be deciphered by some angles and framing of the formal discourse. Telling experiences is not overestimating the things that, by the improbable positivist aspect, would look as an "ode to standard deviation". Assuming the risks of bringing them implies believing that the act of destabilizing the dominant conceptions on school will contribute to thinking without prejudice, far from the impossibilities and the edge of the abyss.

Key words: Research in/of with the quotidian. School quotidian. Social emancipation. Scientific approach.

C

erta vez escrevi uma carta a uma grande amiga agradecendo pelo tempo em que, convivendo e trabalhando juntas, havia aprendise separar...

do, com sua maneira de ser, que o sentir e o fazer não precisavam

Essa aprendizagem cultural, tecida na convivência das lógicas dos espaços político e acadêmico e do fazer por trás desses fins, foi enredada à lógica de meus saberesfazeres de professora, pesquisadora e também de "executiva" na condução dos meios que aportam certos acontecimentos na área da pesquisa educacional, nos quais venho trabalhando.

As vírgulas que separam em categorias os espaços e as identidades profissionais mencionadas não respondem às reais práticas e aos processos de subjetivação nos quais nos enredamos entre os saberesfazeres dos diferentes espaços estruturais (Santos, 1995) no cotidiano, que, ao se entrecruzarem e se imiscuírem, apontam o equívoco de estabelecermos fronteiras fixas. Possivelmente porque não se constituem, nem individual tampouco coletivamente, em territórios demarcados, como nos fez crer 
o paradigma moderno. Suas divisas sujeitam-se à perene dinâmica de sentidos dados por ângulos e percepções culturais que balizam os limites dessas fronteiras.

Magmáticas, entrecruzadas, indefiníveis - salvo sob o aspecto de suas permanências, ao qual não se reduzem, embora permita conceituálas para fins de "viciadas" ${ }^{1}$ compreensões -, esses limites revelam os saberesfazeres de nossas práticas cotidianas que também não se permitem decifrar por ângulos ou enquadramentos que discursam sobre seus extratos.

Somos, contudo, guiados pelos modos de ver e conceber as práticas que reduzem olhos, ouvidos e paladar aos invólucros do que se apresenta. No rastro do cientificismo moderno seguido pelas ciências sociais, resignamo-nos e naturalizamos a prática de conhecer satisfazendo-nos e crendo em rótulos, embalagens que se criam por nós ou por outros para, pretensamente, explicar o viver humano ordinário.

Discutir a relação entre as pesquisas nos/dos/com os diferentes saberesfazeres cotidianos e os modos de conhecer dominantes, especialmente no que tange à relação entre os diferentes saberes e princípios sobre os quais se fundam, não tem a pretensão de ignorar as contribuições que esses modos podem ter trazido à criação do conhecimento em determinados contextos. Contudo, intento que, ao desestabilizar as sensações de pleno conhecimento transmitidas pelos invólucros, poderemos nos propor a desembrulhar as embalagens e provar os sabores que as práticas cotidianas podem nos oferecer ao nos afinarmos com os propósitos de um conhecimento prudente para uma vida decente (Santos, 2004), pensando que as experiências nos podem permitir seguir por caminhos do que melhor nos convém. A pretensão sustenta-se na crença de que a desestabilização pode ter alguma utilidade para desnaturalizar a relação dos sujeitos e seus fazeres com o conhecimento e seus modos clássicos de produção, os quais, passando-se por únicos e legítimos, fizeram-nos perder capítulos e temperos no entendimento das práticas sociais em suas produções ordinárias. ${ }^{2}$

Assim, na pesquisa desenvolvida com o estudo das produções da cultura cotidiana e de sua interveniência na recriação dos currículos, inspirada pelo trecho de Calvino (2000) em epígrafe, proponho considerar que, em nossos modos de ver e conceber a escola, a cultura e o currículo, julgando conhecer/visitar a escola, não percebemos o que ela 
Em busca das escolas na escola: por uma epistemologia das "balas sem papel"

contém ou oculta. Neste sentido, a proposição epistemológica considera uma contribuição mais efetiva das pesquisas desenvolvidas no interior das escolas, na medida em que, ao percebermos o que está para além dos invólucros e discursos sobre a escola, podemos recuperar a dignidade dos que fazem e pesquisam esses cotidianos da educação e da própria escola. Ou seja, finalmente para o que se pensa e faz dela e para ela, permita-lhe ser lugar para todas as escolas e para todos os mundos. ${ }^{3}$

\section{(Des)formatando a vida - a mutilação do ato de pesquisar}

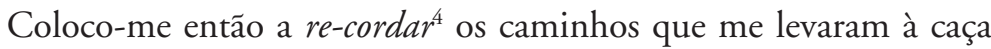
e às narrativas literaturizadas no estudo desenvolvido (Garcia, 2003) que procurou entender as produções culturais nas escolas por seus modos de serfazer e também pelos meus modos de me serfazer pesquisadora nos enigmas cotidianos, embalada pelo tom da melodia de Paulinho da Viola, ${ }^{5}$ acreditando que a vida não é só isso que se vê, é um pouco mais que os olhos não conseguem perceber...

O problema inicia-se, sempre, ao tentar-se situar o que nos interroga em opções teóricas, epistemológicas e metodológicas fechadas. Sob a ânsia de tornar uma argumentação digna de apreciação científica, colocamo-nos ora à caça de teorias e metodologias, ora em cruzada contra paradigmas, modelos científicos e referenciais epistemológicos. Fica-se, assim, a tentar encaixar na ciência a vida, ou não se tem uma pesquisa.

Esse movimento, do qual faz parte a desumanização do conhecimento social, configuraria uma das manifestações dos mecanismos de controle ideológico das ciências sociais, que buscam assegurar a distância e a suposta imparcialidade objetiva que sustentariam a supremacia da razão sobre a arbitrariedade dos dogmas, na cruzada contra o dogmatismo que sustentou o monopólio anterior do conhecimento (Löwy, 1996). Contraditoriamente, a caça persecutória à subjetividade na produção do conhecimento metamorfoseou o paradigma moderno da ciência em novo dogma, legitimado pela cultura ocidental moderna na busca pela onipotência e pela onisciência humanas e assombrado pelo receio do retorno ao monopólio dogmático. Paradoxalmente, esse receio priva a ciência de refletir sobre a pertinência e contribuição de 
manter-se inerte quanto aos seus "valores" e propósitos diante do desperdício da experiência humana e de perceber, no argumento da autoridade científica, uma outra forma de monopólio da verdade e seu conseqüente dogmatismo.

Corroborando esse paradoxo, as opções de pesquisa não podem ater-se à mera tentativa de entender o mundo sem filiações coerentes com o modelo eleito para o desenvolvimento da argumentação. Ainda mais grave seria propor validades múltiplas e casamentos inesperados de teorias e metodologias, tecendo considerações divorciadas das taxionomias científicas modernas, autorizadas e, portanto, as únicas capazes de produzir conhecimentos verdadeiros.

$\mathrm{Na}$ terra fendida ${ }^{6}$ que é defender a produção de conhecimento nos espaços criados pelas lógicas que paradoxalmente procuramos desconstruir, resta-nos pedir licença para falar dos cotidianos que nos recebem, com o cuidado de não reduzir seus temperos ao nosso paladar. Do mesmo modo, é importante pedir licença à etiqueta da ciência quando as circunstâncias e os propósitos nos levarem a cometer gafes imperdoáveis, saboreando um encorpado e seco vinho tinto com um prato que obviamente pedia um branco suave.

A metáfora refere-se à necessária condição de respeito e honestidade para produzir conhecimento com o cotidiano, mas também convida a explorar as possibilidades semânticas e culturais do nosso idioma que, em sua riqueza, permite expressar as diferenças entre os verbos ser e estar, viabilizando-nos contar as realidades estudadas não pelo que elas são, mas pelo como estão. Aos mais atrevidos insinua-se, ainda, a proposta indecente $^{7}$ de marcar a posição sempre subjetiva, mesmo quando se pretende neutra e objetiva, do pesquisador, declarando o lugar de onde fala.

Porém, alerto que não se trata de uma ficção, trata-se, sim, de uma proposta para que se pondere sobre as possibilidades instituintes do cotidiano, representadas aqui pelos saberes que se tecem e que tecem as múltiplas alternativas ao instituído e às culturas próprias de cada escola.

Pretendo, com isso, retomar o alerta de Costa (2002) de que toda pesquisa produz uma realidade, acreditando que, ao declararmos de onde e a que se vem, não se deve canonizar nem se congelar "verdades" enxergadas e produzidas por determinados contextos e propósitos, mas que se tomem as produções na lógica da multiplicidade de aspectos do viver humano. Pondero que tal postura pode contribuir para um modo 
Em busca das escolas na escola: por uma epistemologia das "balas sem papel"

mais humilde e solidário de produção e divulgação de conhecimentos que deixe margem à sua ampliação por práticas epistemológicas cotidianas mais emancipatórias.

Trata-se de buscar o sentirfazer ${ }^{8}$ das práticas cotidianas, as quais, ao não divorciarem os domínios humanos da racionalidade e da emoção - posto que as contingências do dia-a-dia não permitem o privilégio da reflexividade que baliza a separação entre o fazer, o pensar e o sentir -, produzem sentidos e atribuem valores às tarefas corriqueiras, contaminando os saberes com sentimentos e sentidos que contaminarão os fazeres.

A argumentação defende que as práticas cotidianas de produção de saberes, valores e sentidos constituem um movimento de despertar o sol antes do sol raiar, que pela porta de trás da casa vazia chegam mil dias antes de conhecer ${ }^{9}$ as teorias que congelam, selecionam e organizam em permanências o que só se contextualiza e compreende na qualidade de movimento.

Por tal entendimento justifica-se a pertinência e relevância de se estudar os conhecimentos e valores tecidos nas complexas relações estabelecidas nos múltiplos contextos cotidianos (Alves, 2000), nos quais estamos inseridos e que exigem uma reflexão sobre a diversidade de marcas e de valores presentes nas diversas práticas sociais. "Isto é, tudo se entrecruza, tudo se entrelaça para formar a unidade da complexidade; porém, a unidade do 'complexus' não destrói a variedade e a diversidade das complexidades que o teceram" (Morin, 1996, p. 188).

O que implica o estudo das práticas cotidianas buscando suas especificidades, tecidas e construídas histórica, cultural e socialmente pelos sujeitos reais que tecem as realidades concretas. Neste propósito, o paradigma da complexidade não deve ser entendido nem como resposta nem como completude, mas como desafio e luta contra a mutilação, explicando que "a ambição da complexidade é prestar contas das articulações despedaçadas pelos cortes entre disciplinas, entre categorias cognitivas e entre tipos de conhecimento" (idem, p. 176-177).

O caráter epistemológico da proposição implica permitirmo-nos levantar o pano das normas e dos grilhões que cobrem as escolas e suas práticas culturais que, de um olhar janeleiro (Pais, 2003, p. 108), fornecem os elementos inertes que constituem os conceitos deterministas sobre as práticas cotidianas - só passíveis de construção e compreensão 
pelo distanciamento necessário ao enquadramento da totalidade. O levantar desse pano tem o sentido e a intenção, talvez pretensiosa, de perceber essas práticas e seus praticantes por meio de um olhar arruadeiro (idem, ibid.), também com ouvidos curiosos aos seus burburinhos e murmúrios (Certeau, 1994), lançando mão de todos os sentidos (Alves \& Oliveira, 2001), que nos permitam captá-las em suas lógicas, suas nuances, em toda a complexidade das artes de fazer (Certeau, op. cit.).

Isso porque se entende que nessas práticas cotidianas são tecidas redes de saberes e fazeres que roubam e incorporam fios das redes de sabersentir de cada um de seus praticantes. Buscá-las exige cumplicidade na relação para entender as açōes e decisōes. Neste sentido, é preciso mergulhar nos processos e valores vividos e criados por cada um e que aportam seus modos de serfazer e seus saberes. Coloca-se, assim, como exigência para a compreensão das práticas, considerar os "fios" que formam as redes de subjetividades que cada um de nós é (Santos, 1995) e que corroboram o entendimento das nuances e dos caminhos que modificam as estruturas pelos usos e sentidos que delas fazem os praticantes da vida cotidiana. Assim, o estar dentro da escola exige do pesquisador uma autovigilância constante para, nesse mergulho, não perder de vista os perigos do "já sabido" (Oliveira, 2003).

O estudo desse movimento evidencia que "a tessitura das redes de práticas sociais reais se dá por intermédio de 'usos e táticas dos praticantes', que inserem na estrutura social criatividade e pluralidade, modificadores das regras e das relaçôes entre o poder da dominação e a vida dos que a ele estão, supostamente, submetidos" (Oliveira, 2003, p. 48). $\mathrm{O}$ que nos indica, ainda, a possibilidade da produção de fios com valores e princípios emancipatórios na configuração dinâmica dessas redes.

\section{Um saber sem esquinas: cultura e práticas cotidianas na interpreta- ção/ocupação dos espaços}

Um lugar é a ordem (seja qual for) segundo a qual se distribuem elementos nas relações de coexistência. Aí se acha, portanto, excluída a possibilidade, para duas coisas, de ocuparem o mesmo lugar. Aí impera a lei do "próprio" (...). Um lugar é portanto uma configuração instantânea de posiçôes. Implica uma estabilidade (...). Espaço é um cruzamento de móveis. É de certo modo animado pelo conjunto dos movimentos que aí se desdobram. Espaço é um lugar praticado. (Certeau, 1994, p. 202) 
Essa diferença entre lugar e espaço estabelecida pelo pensamento de Michel de Certeau permite compreender o espaço não apenas como lugar ordenado pela totalidade de normas e regras que procuram delimitar a ação dos sujeitos, mas também como produto das complexas tramas e táticas tecidas nos usos e consumos dessas regras pelos sujeitos em suas relaçóes socioculturais, entendendo os espaços, portanto, como "lugares praticados", produzidos culturalmente pelos usos e sentidos que se estabelecem em cada contexto.

Essa compreensão pode por nós ser partilhada ao percebermos, nas mais corriqueiras açôes que praticamos diariamente, os aspectos dos hábitos (saberes?) culturalmente produzidos e empregados quando, por exemplo, trilhamos nossos caminhos cotidianos.

Em certa ocasião, as respostas de um grupo de alunos a um exercício escolar sobre geografia espacial urbana causaram grande inquietação à sua professora, quando os alunos afirmaram, ao longo do exercício proposto, "não saber" o que era uma esquina. Sendo aqueles jovens moradores da cidade e seus transeuntes habituais, é instigante interrogar a respeito dos saberes que operam para deslocarem-se diariamente, já que formalmente não reconheciam alguns elementos básicos da geografia espacial urbana. A explicação a que a professora pôde chegar segue abaixo e deriva de questionamentos posteriores ao susto inicial.

Os jovens de que estamos falando são moradores de uma das muitas favelas que integram a paisagem urbana da cidade do Rio de janeiro. Apesar de localizarem-se no perímetro urbano e em suas principais zonas, as formas singulares de ocupação do espaço que nelas se encarnam formam labirintos, numa disposição do habitar não colonizada pelas convencionalidades de organização oficial dos espaços.

A complexa arquitetura da organização e ocupação das favelas exige uma lógica específica de localização e interpretação daquele espaço geográfico - com ângulos e caminhos pouco perpendiculares -, posto que suas disposições espaciais dialogam menos com as convenções formais de ocupação e localização nesses e desses lugares e mais com as necessidades e referências cotidianas culturalmente produzidas.

Estas lógicas, que deixam passar despercebidas as esquinas, informam com precisão como se movimentar entre becos e vielas da favela para chegar ao "bar do Sr. Jorge" (que fica quase em frente da casa rosa 
da D. Maria, onde funciona uma "escolinha"), saindo da "casa da D. Jacira" (aquela com grade verde na janela, perto do telefone público).

Assim, embora esses jovens, ao se dirigirem para suas escolas, trabalhos ou locais de lazer, transitem por muitas esquinas, elemento corriqueiro na arquitetura urbana do "asfalto", ${ }^{10}$ defini-las é irrelevante, pois, como elemento espacial geográfico, elas não constituem referência relevante no quadro das lógicas de deslocamento e localização "geográfica" utilizadas cotidianamente.

Diante das especificidades dos saberes necessários aos transeuntes para deslocarem-se em seus labirintos, a arquitetura própria das favelas torna parco o conhecimento genérico oferecido pelos conteúdos geográficos formais, os quais, estabelecidos com base nas características espaciais convencionadas pelo urbanismo, são inadequados à interpretação da complexidade desses conglomerados habitacionais.

Saltando e omitindo partes inteiras das regras normativas na ocupação e interpretação dos lugares, as lógicas cotidianas tecem, em suas práticas, um senso de deslocamento e ocupação de espaços, criando significados para estes, diferentes dos sentidos, colonizados pelas regras de organização e interpretação "convencionais" das cidades, oferecidos pelos saberes formalizados que constituem os conteúdos do currículo escolar proposto.

Também nas escolas, os estilos de ação intervêm num campo que os regula, criando maneiras de utilizar a ordem imposta (Certeau, 1994, p. 93). O uso permite, portanto, criar outros sentidos culturais, colocando em diálogo, nem sempre autorizado ou reconhecido, referências, saberes e valores de dentro e de fora das escolas. Isso, possivelmente, porque o uso não reconhece as fronteiras, nem as grades do portão da escola, que separariam os saberes. As redes de saberes, produtoras de formas culturais e subjetividades, seguem, assim, saltando, também nas escolas, as esquinas das regras de organização do conhecimento.

Percebê-las implica percebermos também os tantos saberes nelas enredados, os quais, por capricho da ciência, foram separados "salomonicamente" entre conhecimento e senso-comum, ou se assim preferirmos - seguindo o alerta de Santos (1993) - na metáfora representada por D. Quixote e Sancho Pança.

No movimento de levantar o pano e bisbilhotar o cotidiano é preciso estar com olhos e ouvidos atentos para perceber/captar no dito e no 
Em busca das escolas na escola: por uma epistemologia das "balas sem papel"

feito, ou no que não se diz mas se faz, ou ainda, no que não se faz mas se diz, os valores que guiam as práticas reais e suas crenças, que não raramente se escondem sob o pano de discursos e práticas legitimados, entrevendo sob eles outros discursos e práticas do não-dito ou do que não se conserva (Certeau, 1994).

Numa escola municipal de Ensino Fundamental em que se desenvolveu parte da pesquisa, os murais improvisados com barbante e pregadores ocupam alguns dos corredores dos andares superiores. Nesses espaços o que não é conteúdo oficial, como o futebol, circula e é divulgado. Caminhando pelos corredores, escadas e salas de aula, é possível ao visitante eventual perceber o conteúdo trabalhado por cada turma, os temas gerais contemplados pela escola e os demais assuntos que insistem em atravessar os portóes gradeados do espaço escolar e colocar-se entre o hall de conhecimentos importantes, claro que cada coisa no seu devido lugar.

Se essa percepção, passível aos olhares mais distraídos, denota uma imagem que a escola procura destacar de instituição que contempla sua função - dando conta da oficialidade, mas que reconhece o discurso da especificidade, reafirmando sua atenção às realidades da comunidade que atende -, ela também conota que os discursos oficiais são trazidos para as práticas cotidianas, mas que a apropriação que se faz deles dialoga necessariamente com os valores individuais e coletivos culturalmente produzidos em cada espaço praticado.

Esses valores, que falam ao grupo de profissionais da escola sobre o reconhecimento da validade dos tantos saberes, oficializados ou não, também permitem a cada um deles, individualmente, indicar aos seus alunos o que importa abordar quando o tema em questão é, por exemplo, a saúde. Uma simpática e extrovertida professora confeccionou com sua turma um cartaz na face externa da porta da sala de aula que ocupam, no qual se podia ler sorrir é o melhor remédio, levando sua turma a pesquisar sobre os benefícios do riso para a saúde, para além das prescrições formais de conteúdo. Se, por um lado, a arquitetura dessa e de outras escolas municipais da cidade do Rio de Janeiro leva a pensar sobre o conteúdo de disciplinamento e controle insinuados por uma pesada porta e sua ostensiva tranca acessível apenas de fora da sala, por outro lado, as práticas desenvolvidas levam a considerar como as estratégias de regulação, materializadas ou não, podem ter minimizado seus efeitos por meio desses diferentes usos. 
Portanto, essa busca pelos usos implica não se satisfazer com as imagens aparentes ou com os discursos diretos e exige buscar as redes de subjetividades presentes nas práticas cotidianas e em suas articulações. A necessária incorporação dos saberesfazeres cotidianos, a reboque da compreensão de suas múltiplas articulações presentes na formação das subjetividades que emergem nos diversos contextos das práticas sociais, leva a ponderar que,

(...) se a rede de subjetividades que constitui cada um de nós se tece nos diversos espaços estruturais nos quais estamos inseridos, isso se dá porque eles estão permanentemente articulados e sempre presentes na nossa vida cotidiana, da qual são elementos constitutivos. (Oliveira, 2003, p. 55)

Incorporando esses aspectos na pesquisa, o uso de entrevistas realizadas com professoras nos contextos estudados contribuiu para entrever os vínculos, nem sempre lineares, entre os valores tecidos em suas trajetórias profissionais e pessoais e as escolhas que fazem parte da elaboração e efetivação das práticas político-pedagógicas que tecem cotidianamente. Foi possível, ainda, perceber, como procedimento metodológico fundamental, a relevância de trazer esses relatos e narrar essas e muitas outras experiências vivenciadas por nós e por elas (professoras) para buscarmos os indícios de uma lógica de produção da ação de sujeitos reais nas práticas cotidianas, escolares ou não. Seria, assim, considerar esse espaço ordenado pela totalidade de normas e regras que procuram delimitar a ação desses sujeitos, mas também as complexas tramas e táticas tecidas no uso e consumo dessas regras (Certeau, 1994) pelos sujeitos em suas relações socioculturais (Oliveira, 2001).

Contudo, tais aspectos não se deixam perceber na clássica relação pesquisador/pesquisado, exigindo, tanto para entrever os indícios nas entrevistas ou conversas dos contextos estudados quanto na narrativa dos relatos e experiências, uma relação de cumplicidade com os propósitos de valorização das práticas ordinárias. Renuncia-se, desse modo, à busca pelas carências constatadas com relação a modelos e idealizações das práticas e dos espaços e passa-se a interrogar e buscar o que está presente nas materializações e nos valores que tecem as práticas nas e pelas contingências dadas pelo cotidiano.

Trata-se de perceber as escolas e o que nelas se produz pelo que está presente sem desviar as atenções para a busca de carências, algu- 
Em busca das escolas na escola: por uma epistemologia das "balas sem papel"

mas identificadas apenas na relação dicotômica com as idealizações próprias dos modelos de "Ser".

Estudar o cotidiano pode ser, então, entendido como um ato de enamoramento, um jogo de sedução, no qual as sutilezas que se insinuam em gestos e murmúrios do ordinário permitem uma aproximação do social que se apresenta. Tais sedução e enamoramento, contudo, não implicam asserções ingênuas de pesquisa. $\mathrm{Na}$ medida em que nos propomos a perceber o caminhar e o fazer cotidiano das escolas e, especialmente, abdicamos da ansiedade de constituir sobre elas um conhecimento universal, assume-se, concomitantemente, a possibilidade de compreender que ao cotidiano, assim como ao enamoramento, cabe o enredo quem me disse que eu era riso sempre e nunca pranto? ${ }^{11}$

Neste sentido, para entender o que diversifica e pluraliza os cotidianos das escolas, com os múltiplos saberes neles presentes, foi de extrema importância substituir os procedimentos generalizantes, considerados insuficientes para o estudo da pluralidade e da diversidade das práticas concretas e dos processos de tessitura de conhecimentos, por procedimentos vinculados às metodologias qualitativas em educação, principalmente as que permitem estudar e validar os saberes do cotidiano (grifo meu). ${ }^{12}$

A pesquisa de campo, inscrita no quadro de elaboração de minha dissertação de mestrado, ${ }^{13}$ foi desenvolvida em escolas municipais e privadas do município do Rio de Janeiro, buscando-se nas práticas cotidianas nelas realizadas suas especificidades e singularidades, as quais, invisíveis às reflexões cientificistas, formam as alternativas reais no seio dos currículos praticados, bem como os indícios de práticas emancipatórias captáveis nesses fazeres cotidianos.

Tal postura permitiu, ao desconstruir ou não se satisfazer com as concepções arraigadas e colonizadas sobre a vida nas escolas, pintá-las com matizes improváveis nessas concepções, levando a leitura e a interpretação do estudo às múltiplas dimensões da pluralidade da vida real que compõem a riqueza das práticas cotidianas.

A vertigem desse movimento permite, ao menos, confundir nossos conceitos. Assim como, ao visitar Tamara, o visitante deixa-a sem conhecê-la, interrogamo-nos se, de fato, o que conhecemos sobre a escola não seria, apenas, um "denso invólucro de sinais e o que ela contém ou oculta, [permanecemos] sem tê-lo sabido" (Calvino, 2000, p. 18). 
Isso significa, então, que é preciso colocarmo-nos a bisbilhotar por baixo dos panos de uma realidade em que na superfície há o que "todo dia ela faz tudo sempre igual", tentando ver o que nela se passa mesmo quando "nada se passa" (Pais, 2003, p. 33). Sobre o caráter da ação de buscar no real os aspectos velados pelas formas de pesquisar o social, sobre as quais se coloca essa denúnciaproposta que busco incorporar, Ferraço (2003, p. 163) auxilia-nos na compreensão de que “(...) os estudos e pesquisas 'com' os cotidianos (...) expressam o 'entremeado' das relações das redes cotidianas, os diferentes 'espaçostempos' vividos pelos sujeitos cotidianos. Acontecem nos processos de 'tessitura' e contaminação dessas redes".

Meter-se por baixo dos panos a ouvir os murmúrios dessa vida cotidiana convertendo-a em permanente surpresa (idem, p. 26), implica perceber as variedades que nela se apresentam, o que há de diferente e heterogêneo e que nos exige a incorporação do múltiplo como fonte e conceito. Alves e Oliveira (2001) chamam, a este pré-requisito para a compreensão do cotidiano, beber em todas as fontes, que, dado pela exigência de perceber os aspectos antes negados desse contexto, implica interrogarmos os limites dos conceitos e das teorias e do que, para as especificidades do cotidiano e de sua compreensão que se pretende captar, precisa ser entendido como fonte. Isso certamente consiste em revirar as concepções de conhecimento e de produção de conhecimento para a incorporação dessa dimensão do múltiplo. Como bem nos fala a autora:

A formação do pensamento ocidental dominante, que exige "ver para crer", levou à grande dificuldade em se aceitar o múltiplo: os múltiplos sentidos, os múltiplos caminhos, os múltiplos aspectos, as múltiplas regras, as múltiplas fontes. Dessa maneira, pensar "ao contrário", em ciência, tem exigido uma discussão sobre o que pode ser aceito como fonte de conhecimento. (Alves \& Oliveira, 2001, p. 26)

Entendendo com Pais (2003) que nos interessa mostrar em lugar de demonstrar, essa opção, ao passo que nos isenta das quantificações - que na generalização conseqüente significariam a perda da riqueza que tanto buscamos -, compromete-nos a desancorarmo-nos de "quadros e conceitos (ou preconceitos) de partida, bem assim como [de] hipóteses rígidas que à força se procura demonstrar num processo de duvidoso alcance em que o conhecimento explicativo se divorcia do conhecimento descritivo e compreensivo" (idem, p. 30). Neste senti- 
Em busca das escolas na escola: por uma epistemologia das "balas sem papel"

do, essa tendência pode nos mostrar algumas pistas dessa busca. As perspectivas deste estudo nos guiam às possibilidades trazidas por Alves e Oliveira (2001). Ao falar das exigências impostas à metodologia, pelas preocupações teórico-metodológico-epitemológicas de pesquisar o cotidiano, a autora conta-nos sobre essas experiências que

(...) para desenvolver esses trabalhos, no uso de metodologias de origem sociológica são trançadas outras de origem nos campos histórico, antropológico, etnográfico, comunicacional, psicológico, etológico etc., pois compreende-se que o estudo desses espaços/tempos exige a incorporação da sua "complexidade", em todos os processos (Morin, 1994; 1996; 1999). Parte-se, portanto, da idéia da necessidade de um trabalho que desenvolva métodos e metodologias complexos e enredados. (Alves \& Oliveira, 2001, p. 11)

Simultaneamente, isso significa que, por um lado, conceitos e teorias devem ser entendidos como limites, colocados à disposição da capacidade criadora de quem pesquisa (idem, ibid.), e, por outro lado, exigem-nos

(...) a ampliação e a complexificação do que vamos considerar como fonte de conhecimento. Para além daquilo que pode ser agrupado e contado (no sentido de numerado), como antes aprendemos, vai interessar aquilo que é "contado" (pela voz que diz), pela memória: o caso acontecido que parece único (e que por isso o é) a quem o "conta"; o documento (caderno de planejamento, caderno de aluno, prova ou exercício dado ou feito etc.) raro porque guardado quando tantos iguais foram jogados porque "não eram importantes" e sobre o qual se "conta" uma história diferente, dependendo do trecho que se considera; a fotografia que emociona, a cada vez que é olhada, e sobre a qual se "contam" tantas histórias, dos que nela aparecem ou estão ausentes e da situação que mostra ou daquela que "faz lembrar". (Alves \& Oliveira, 2001, p. 27)

A longa citação à qual me permiti nesta discussão se justifica pelo entendimento de que apenas ela poderia expor os aspectos, o sentido, de estudar no cotidiano e com esse cotidiano que se pretende alcançar. Isso nos coloca a pensar nas dimensões do "ver" e do "crer" citados inicialmente por Alves e Oliveira (idem) para a "possibilidade de entrada e articulação de novos fios de saberes ao anteriormente sabido" (Oliveira, 2003, p. 73), ou seja, na proposição trazida por Alves e Oliveira (op. cit.) para a compreensão do que é preciso à pesquisa no/do cotidi- 
ano incorporar como fonte, inclui-se o entendimento da dimensão do emocional ao que é produção humana (Maturana, 1999), que se imiscui ao racional no viver cotidiano.

Concordando novamente com Oliveira (2003), ao trazer para esta discussão as contribuições de Von Foerster (1996), na compreensão oposta à máxima da modernidade representada no pensamento de São Tomé do "ver pra crer" - que povoa nossas explicações e compreensões do mundo desde que somos crianças na expressão, que inclui suas variantes, "só acredito vendo - de que somos capazes de ficar cegos ao que não acreditamos existir. Essa proposição é explicada por Von Foerster (ibid.), nas palavras de Oliveira (op. cit., p. 73), como se devendo ao fato de nossa retina estar sujeita a um controle central, o que exige que, para ver, acreditemos e compreendamos o que vemos, ou seja, "é preciso crer pra ver". $\mathrm{O}$ que toma para nós o sentido de que, se estivermos arraigados a noçôes, conceitos e teorias que nos explicam a realidade que tomamos, é possível ficarmos "cegos" diante do que nela há e acontece para além dessas molduras.

Desancorados dessas molduras, ao nos debruçarmos sobre as questões que permeiam ou mesmo definem um currículo em sua materialização cotidiana, deparamo-nos com aspectos que podem nos levar a entrever (Ginzburg, 1989) as redes de representaçôes e ações (Ferraço, 2001) presentes nos currículos praticados, logo, do que de fato se produz/ aprende/ensina nas escolas.

Neste sentido, adequar-se à "caça" desses aspectos é fazer opção por procedimentos, ferramentas e posturas, na relação pesquisador/ pesquisado que permitam mergulhar com todos os sentidos (Alves \& Oliveira, 2001, p. 15) no estudo desse cotidiano. Além de incorporar a noção de complexidade e de buscar apoio teórico em autores que possibilitam outras formulações sobre as concepções que temos arraigadas pelos processos que nos formaram, será necessário, ainda, ampliar a noção do que iremos tomar como fonte de conhecimento. Assim, será importante considerar elementos que nos permitam perceber o que há de plural e heterogêneo, portanto rico e válido, para o estudo que se pretende, será necessário incorporar o que antes fora expurgado da análise, dos fins e do discurso científico. Será, então, recuperar as contradições e incoerências, a irracionalidade e a incompletude, permitirmo-nos interrogar em lugar de responder e reintroduzir a incerteza sobre os fenômenos humanos. 
Em busca das escolas na escola: por uma epistemologia das "balas sem papel"

Consideramos, para tal, aspectos múltiplos, para além do que é inerte e pode ser dissecado no lugar científico (Certeau, 1994, p. 81), que permitem ao estudo mergulhar na complexidade do cotidiano, evidenciando a validade dos saberes que nele se tecem. Essa opção, que impõe a não-eliminação dos autores e do espaço de suas táticas (idem, ibid.), segue na contramão da constituição de um "lugar científico que tem, na condição prévia de qualquer análise, a necessidade de poder 'transferir' para ali os objetos que se deve estudar" (idem, ibid.).

Narrar essas experiências em uma pesquisa, contando histórias dessas escolas, não configura uma circunstância de estudos de casos isolados, sobretudo significa uma posição ingênua de superestimar o que, pelo improvável aspecto "positivo", pareça-nos uma "ode ao desvio-padrão". Assumir os riscos de trazer esses aspectos implica acreditar que o simples ato de desestabilizar as concepçóes arraigadas sobre a escola pode contribuir para a pensarmos sem "pré-conceitos", longe das impossibilidades e da beira do abismo. O plano é espalhar essas histórias pelo vento, para quem as escutar lembrar de outras e também as contar, numa epidemia que confunda e contamine nossas concepções e ações sobre as escolas, nas escolas e com as escolas.

\section{Recebido em outubro de 2006 e aprovado em março de 2007.}

\section{Notas}

1. A esse respeito ver a discussão, com a defesa intransigente de alguns pesquisadores, dos paradigmas cientificistas da modernidade, desenvolvida em Inês Barbosa de Oliveira, "Criação curricular, autoformação e formação continuada no cotidiano escolar", em Carlos Eduardo Ferraço, Cotidiano escolar, formação de professores e currículo, São Paulo: Cortez, 2005.

2. A expressão, incorporada ao estudo que realizei, inspira-se no pensamento de Certeau (1994) e refere-se às produções identitárias e de saberes na tessitura cotidiana das práticas e dos sentidos atribuídos por seus praticantes.

3. Citando a fala do subcomandante Marcos, La marcha del color de la tierra (comunicados, cartas y mensajes del Ejército Zapatista de la Liberación Nacional del 2000 al 2 de abril del 2001), México: Rizoma, 2001; apud Candau (2002).

4. Do latim re-cordis, tornar a passar pelo coração (Galeano, 2003, p. 11).

5. Paulinho da Viola e Hermínio Bello de Carvalho, "Sei lá Mangueira", em A bossa eterna de Elizete e Ciro, Copacabana Discos, 1991.

6. A metáfora (Barreto, 2004), que faz menção aos abismos criados nos acidentes geográficos formados pelos penhascos de basalto da Serra do Mar, é aqui utilizada para referir-se ao 
movimento vertiginoso de desestabilização das linhas e dos platôs do pesquisar, que tanto guiam como amarram.

7. Expressão consagrada depois de ter sido título de filme estrelado por Demi Moore e Robert Redford.

8. Na argumentação sustentada, sentir dialoga tanto com a idéia das emoções que compõem o SER humano quanto com o movimento de atribuir, culturalmente, sentidos em/por um coletivo. Considera-se, assim, o movimento de criação cultural de sentidos balizado pela relação de um dado coletivo com a equalização da emoção no/do humano.

9. Chico Buarque e Edu Lobo, "Valsa brasileira", 1987.

10. A expressão, cotidianamente utilizada pelos cariocas, identifica, nos usos da linguagem, as demarcaçōes que não se localizam apenas pelos receptáculos físicos que ora separam ora unem a ocupação disciplinarizada e estática das institucionalidades físicas e operacionais do perímetro urbano e o aparente improviso das intervençōes e apropriaçōes, também físicas e operacionais, intrínseco à arquitetura anima das favelas.

11. Chico Buarque, "Como se fosse a primavera”, 1999 ("De que callada manera” - Pablo Milanes, Nicolás Guillén).

12. Grifo meu.

13. A pesquisa intitulada "Escolas e culturas: as possibilidades emancipatórias dos/nos currículos praticados" foi realizada entre 2001 e 2003 e deu origem à dissertação de mestrado. Muito do material empírico coletado, não utilizado na ocasião, vem permitindo o aprofundamento das discussões a respeito do cotidiano escolar.

\section{Referências bibliográficas}

ALVES, N. O romance das aulas. Revista Movimento - Profissão docente: teoria e prática. Niterói, n. 2, p. 7-32, set. 2000.

ALVES, N.; OLIVEIRA, I.B. Pesquisa noldo cotidiano das escolas: sobre redes de saberes. Rio de Janeiro: DP\&A, 2001.

BARRETO, P.S.M. Terra fendida: problemas da matéria e das criaçóes. In: REUNIÃO ANUAL DA ASSOCIAÇÃO NACIONAL DE PÓSGRADUAÇÃO E PESQUISA EM EDUCCAÇÃO (ANPED), 27., 2004, Caxambú. Anais... Caxambu, 2004. CD-ROM.

CALVINO, I. As cidades invisiveis. Lisboa: Teorema, 2000.

CANDAU, V.M. Multiculturalismo, educação e direitos humanos. In: ENCONTRO NACIONAL DE DITATICA E PRÁTICA DE ENSINO (ENDIPE), 11., 2002, Goiânia. Actas do... Goiânia, 2002. CD-ROM.

CERTEAU, M. A invenção do cotidiano 1: artes de fazer. Petrópolis: Vozes, 1994. 
Em busca das escolas na escola: por uma epistemologia das "balas sem papel"

COSTA, M.V. Caminhos investigativos II. Rio de Janeiro: DP\&A, 2002.

FERRAÇO, C.E. Ensaios de uma metodologia efêmera: ou sobre as várias maneiras de se sentir e inventar o cotidiano. In: Alves, N.; OliveIRA, I.B. Pesquisa noldo cotidiano das escolas: sobre redes de saberes. Rio de Janeiro: DP\&A, 2001.

FERRAÇO, C.E. Eu “caçador de mim”. In: Garcia, R.L. (Org.). Método: pesquisa com o cotidiano. Rio de Janeiro: DP\&A, 2003.

GALEANO, E. O livro dos abraços. Porto Alegre: L\&PM, 2003.

GARCIA, A. Escolas e culturas: as possibilidades emancipatórias dos/nos currículos praticados. 2003. Dissertação (Mestrado) - Programa de Pós-Graduação em Educação, Faculdade de Educação, Universidade Estadual do Rio de Janeiro, Rio de Janeiro.

LÖWY, M. Ideologias e cência social: elementos para uma análise marxista. São Paulo: Cortez, 1996.

MATURANA, H. Emoções e linguagem na educação e na política. Belo Horizonte: UFMG, 1999.

MORIN, E. Ciência com consciência. Rio de Janeiro: Bertrand Brasil, 1996.

OLIVEIRA, I.B. Certeau e as artes de fazer: as noções de uso, tática e trajetória na pesquisa em educação In: Alves, N.; Oliveira, I.B. Pesquisa noldo cotidiano das escolas: sobre redes de saberes. Rio de Janeiro: DP\&A, 2001.

OLIVEIRA, I.B. Currículos praticados: entre a regulação e a emancipação. Rio de Janeiro: DP\&A, 2003.

PAIS, J.M. Vida cotidiana: enigmas e revelações. São Paulo: Cortez, 2003.

SANTOS, B.S. Entre Dom Quixote e Sancho Pança. Revista Crítica de Ciências Sociais, Coimbra, n. 37, p. 5-10, jun. 1993.

SANTOS, B.S. Pela mão de Alice: o social e o político na pós-modernidade. São Paulo: Cortez, 1995. 
SANTOS, B.S. (Org.) Conhecimento prudente para uma vida decente. São Paulo: Cortez, 2004.

VON FOERSTER, H. Visão e conhecimento: disfunções de segunda ordem. In: Schnitman, D.F. Novos paradigmas, cultura e subjetividade. Porto Alegre: Artes Médicas, 1996. p. 59-74. 